\title{
Alstom 3-MW Wind Turbine Installed at NWTC
}

\author{
Test data will be used to validate advanced turbine design \\ and analysis tools.
}

NREL signed a Cooperative Research and Development Agreement with Alstom in 2010 to conduct certification testing on the company's 3-MW ECO 100 wind turbine and to validate models of Alstom's unique drivetrain concept. The turbine was installed at NREL's National Wind Technology Center (NWTC) in October 2010 and engineers began certification testing in 2011. Tests to be conducted by NREL include a power quality test to finalize the International Electrotechnical Commission (IEC) requirements for type certification of the $60-\mathrm{Hz}$ unit. The successful outcome of this test will enable Alstom to begin commercial production of ECO 100 in the United States. NREL also will obtain additional measurements of power performance, acoustic noise, and system frequency to complement the $50 \mathrm{~Hz}$ results previously completed in Europe.

After NREL completes the certification testing on the ECO 100, it will conduct longterm testing to validate gearbox performance to gain a better understanding of the machine's unique ALSTOM PURE TORQUE ${ }^{\text {TM }}$ drivetrain concept. In conventional wind turbines, the rotor is supported by the shaft-bearing gearbox assembly. Rotor loads are partially transmitted to the gearbox and may reduce gearbox reliability. In the ALSTOM PURE TORQUE concept, the rotor is supported by a cast frame running through the hub, which transfers bending loads directly to the tower. Torque is transmitted to the shaft through an elastic coupling at the front of the hub. According to Alstom, this system will increase wind turbine reliability and reduce operation and maintenance costs by isolating the gearbox from rotor loads.

Gearbox reliability has challenged the wind energy industry for more than two decades. Gearbox failures require expensive and time-consuming replacement, significantly increasing the cost of wind plant operation while reducing the plant's power output and revenue. To solve gearbox reliability issues, NREL launched a Gearbox Reliability Collaborative (GRC) in 2006 and brought together the world's leading turbine manufacturers, consultants, and experts from more than 30 companies and organizations. GRC's goal was to validate the typical design process-from wind turbine system loads to bearing ratings - through a comprehensive dynamometer and field-test program. Design analyses will form a basis for improving reliability of future designs and retrofit packages. Through its study of Alstom's Eco 100 gearbox, NREL can compare its GRC model gearbox with Alstom's and add the results to the GRC database, which is helping to advance more reliable wind turbine technology.

Technical Contact: Jeroen van Dam, jeroen.van.dam@nrel.gov

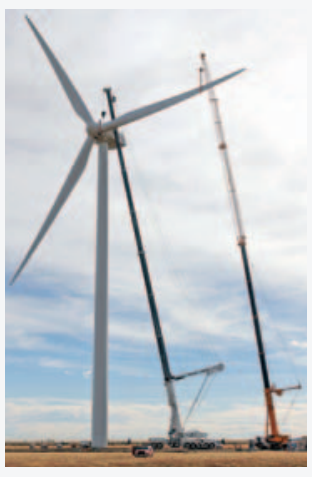

The 3-MW Alstom wind turbine was installed at NREL's NWTC in October 2010. Photo by Lee Jay Fingersh, NREL/ PIX 18496

\section{Key Research Results}

Achievement

NREL researchers are working with Alstom to validate the performance of Alstom's 3-MW wind turbine. The turbine was installed for testing at the NWTC in 2010 and certification tests, which included a power quality test to IEC standards, will be conducted in 2011. NREL will also obtain additional measurements for power performance, acoustic noise, and system frequency.

\section{Key Result}

NREL's certification testing will enable Alstom to begin commercial production of its new machine in the United States and the test data will provide additional validation of Alstom's unique PURE TORQUE drivetrain concept.

Potential Impact

Gearbox reliability has challenged the wind energy industry for more than two decades. Gearbox failures require expensive and timeconsuming replacement, significantly increasing the cost of wind plant operation while reducing the plant's power output and revenue. NREL's efforts to increase the understanding of gearbox failures and identify gaps in the design process will form a basis for improving reliability and reducing operation and maintenance costs.

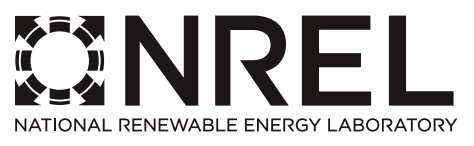

1617 Cole Boulevard | Golden, Colorado 80401 | 303-275-3000 | www.nrel.gov

\section{NREL is a national laboratory of the U.S. Department of Energy, Office of Energy Efficiency and Renewable Energy, operated by the Alliance for Sustainable Energy, LLC.}

NREL/FS-5000-52663 • September 2011 